\title{
Effect of metabolic syndrome on coronary heart disease in rural minorities of Xinjiang: a retrospective cohort study
}

\author{
Changjing $\mathrm{Li}^{\dagger}$, Jia He ${ }^{\dagger}$, Bin Wei, Xianghui Zhang, Xinping Wang, Jingyu Zhang, Kui Wang, Yunhua Hu, Lati Mu, \\ Yizhong Yan, Jiaolong Ma, Yanpeng Song, Heng Guo, Rulin Ma* and Shuxia Guo*
}

\begin{abstract}
Background: Metabolic syndrome is diagnosed by a cluster of risk factors that associated with an increased risk of coronary heart disease (CHD). We aimed to explore the impact of and interactions between individual metabolic syndrome components on the risk of CHD in Xinjiang.

Methods: The baseline population included 7635 participants. The degree to which the components increase the risk of CHD and the multiplicative interactions between them were assessed using hazard ratios (HRs) and 95\% confidence intervals $(\mathrm{Cls})$. Additive interactions were appraised by the relative excess risk due to interaction, synergy index (SI), and attributable proportion of interaction.

Results: A total of 304 CHD patients were enrolled from rural residents of Xinjiang. Elevated blood pressure (HR $1.81 ; 95 \% \mathrm{Cl} 1.35-2.44)$ and elevated fasting blood glucose (FBG) (HR 1.82; $95 \% \mathrm{Cl} 1.38-2.38)$ increased the risk of CHD after adjustment for confounding factors. We found a positive additive interaction (SI 1.14; $95 \% \mathrm{Cl} 0.51-2.51$ ) between elevated blood pressure and elevated FBG, but none were significant. As the number of components increased, the risk of CHD increased. The combinations of [high triglycerides (TG) + low high-density lipoprotein cholesterol (HDL-C) + elevated FBG + large waistline] (HR 4.26; 95\% Cl 1.43-12.73) and [elevated blood pressure + elevated FBG + low HDL-C + large waistline] (HR 1.82; 95\% Cl 1.38-2.38) increased the risk of CHD.
\end{abstract}

Conclusions: We provide evidence that elevated blood pressure and elevated FBG are independent risk factors for $\mathrm{CHD}$ and it might be necessary to maintain the normal waistline for preventing CHD.

Keywords: Coronary heart disease, Metabolic syndrome, Interaction, Risk factor, Epidemiology

\section{Background}

The mortality rate of CHD has increased by $40.1 \%$ from 2006 to 2016, with CHD accounting for $17.8 \%$ of total deaths in China [1]. Meanwhile, the prevalence of risk factors for CHD has been increasing. CHD cannot be completely cured by clinical treatment, but it can be effectively prevented by controlling its risk factors and

\footnotetext{
* Correspondence: gsxshzu@sina.com

${ }^{\dagger}$ Changjing Li and Jia He are joint first authors.

Department of Public Health, Shihezi University School of Medicine, Shihezi, China
}

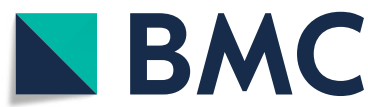

() The Author(s). 2020 Open Access This article is licensed under a Creative Commons Attribution 4.0 International License, which permits use, sharing, adaptation, distribution and reproduction in any medium or format, as long as you give appropriate credit to the original author(s) and the source, provide a link to the Creative Commons licence, and indicate if changes were made. The images or other third party material in this article are included in the article's Creative Commons licence, unless indicated otherwise in a credit line to the material. If material is not included in the article's Creative Commons licence and your intended use is not permitted by statutory regulation or exceeds the permitted use, you will need to obtain permission directly from the copyright holder. To view a copy of this licence, visit http://creativecommons.org/licenses/by/ 40 . The Creative Commons Public Domain Dedication waiver (http//creativecommons.org/publicdomain/zero/1.0/) applies to the data made available in this article, unless otherwise stated in a credit line to the data.

treating diseases known to contribute to this propensity. Metabolic syndrome is diagnosed by a range of components, including obesity, elevated blood pressure, elevated serum triglycerides, low $H D L-C$, and elevated fasting blood glucose $[2,3]$.

Metabolic syndrome is associated with an increased risk of $\mathrm{CHD}[4,5]$, and a meta-analysis report indicates that the hazard ratio of CHD events in patients with metabolic syndrome is $1.65(1.37-1.99)$, while the HR of CHD deaths is 1.60 (1.28-2.01) [6]. In addition, studies have shown that the contribution of metabolic syndrome 
and its components to the risk of CHD should be treated equally, and that their combined effect may have a stronger impact on CHD [7-9]. Another study found that the risk of CHD increases with the number of components [10]. However, the above research needs to be further confirmed in the Xinjiang population.

Ethnic minorities account for $64.90 \%$ of Xinjiang's total population, and the Han community accounts for $35.10 \%$ of Xinjiang's total population. However, there are less research on ethnic minorities. Therefore, we choose to analyze the major ethnic minority population in Xinjiang (the top two ethnic minority groups in Xinjiang: Uygur 73.83\%, Kazakh 13.51\%) [11]. Due to lack of economic development, difficult living environment, and specific diet (high salt, high fat, high carbohydrates) [12], the prevalence of metabolic syndrome among the population of Xinjiang is higher than that among the national population in China [13]. Moreover, as metabolic syndrome component indicators are simple to obtain, it is essential to analyze the effect of metabolic syndrome on coronary heart disease in this population.

In the present study, we analyzed the aggregation of its components and the effects of interactions between metabolic syndrome components on the risk of CHD in this population, which can be instrumental in the prevention and control of CHD.

\section{Methods}

\section{Study Population}

The survey among Kazakhs and Uyghurs began in April 2009 and was followed up in December 2013, April 2016, and August 2017 in Xinyuan County and Jiashi County. We used a stratified sampling method to select the corresponding villages ( 9 villages in the Halabra Township, 6 villages in the Nalati Township, and 12 villages in the Jiangbazi Township). We followed 7635 participants (3546 Uighurs, 4089 Kazakhs) above the age of 18 years who had lived in the villages for at least 6 months. All participants provided informed consent. The total response rate was $87.5 \%$ (88.6\% in Uygur and $86.5 \%$ in Kazakh). We further excluded 133 participants who already had CHD before April 2009 and 220 participants with incomplete blood samples or physical information. Finally, we included 7282 participants in this study. The survey was approved by the Ethical Review Board of the First Affiliated Hospital of Shihezi University School of Medicine (IERB No. SHZ2010LL01) and operations and methods were carried out in accordance with the relevant guidelines and regulations.

\section{Diagnostic criteria for CHD}

Patients diagnosed with CHD needed to meet the criteria for having their first CHD hospitalizations during the study period due to one or more of the following: coronary artery atherosclerosis, coronary interventional therapy, angina pectoris, myocardial infarction, and sudden cardiac death. The patients of CHD were determined based on self-reported questionnaire responses, medical insurance records, and local hospital discharge records from 2009 to 2017. Patients with self-reported manifestations of CHD findings required a certificate of diagnosis from a medical institution in their township during the investigation.

\section{Epidemiological survey and biochemical measurements}

Data of participants were collected using a questionnaire. The detailed questions on the questionnaire covered demographics, smoking status, alcohol consumption status, and personal and family history of disease. During the interview, each participant's waistline was measured by uniform standardized methods. The above measurement and blood sample collection methods have been previously described [14]. The biochemical parameters from blood samples included TG, high-density lipoprotein cholesterol, and FBG, which were analyzed using an automatic biochemical analyzer (Olympus AU 2700; Olympus Diagnostics, Hamburg, Germany).

\section{Definition of metabolic syndrome}

Our study used the National Cholesterol Education Program (NCEP) definition for diagnosis of metabolic syndrome in order to achieve the goal of controlling highrisk populations to reduce development of CHD [15]. The individuals were diagnosed as having metabolic syndrome if 3 or more of the 5 components were present, as follows: (1) waistline ( $\geq 90 \mathrm{~cm}$ in men $\geq 80 \mathrm{~cm}$ in women); (2) $\mathrm{FBG} \geq 5.6 \mathrm{mmol} / \mathrm{L}$ or a diagnosis of diabetes; (3) systolic blood pressure (SBP) $\geq 130 \mathrm{mmHg}$; diastolic blood pressure (DBP) $\geq 85 \mathrm{mmHg}$, or use of antihypertensive drugs; (4) high TG ( $\geq 1.7 \mathrm{mmol} / \mathrm{L})$; and (5) low HDL-C cholesterol $(<1.04 \mathrm{mmol} / \mathrm{L}$ in men and $<$ $1.30 \mathrm{mmol} / \mathrm{L}$ in women) [2].

\section{Statistical analysis}

Significant differences in baseline characteristics were found using the $X^{2}$ test and $t$ test. Evaluation of association between metabolic syndrome components and CHD risk was assessed using multivariate Cox regression. The above multivariable Cox model were tested by the proportional hazard assumption of Cox models. Data were analyzed using Statistical Product and Service Solutions (SPSS) version 24.0 (Chicago, Illinois, USA). Statistical significance was defined as a $p$-value $<0.05$ and all statistical tests were two-sided.

Multiplicative interactions were evaluated by the multiplicative SI and its 95\% CI (the 95\% CI of multiplicative SI not including 1 indicate significant 
multiplicative interaction), which was calculated by entering the two risk factors and their interaction terms into the Cox regression. We appraised additive interactions by $95 \% \mathrm{CI}$ of three indices; the following conditions indicate exist additive interaction: relative excess risk due to interaction (RERI) not including 0 , attributable proportion of interaction (AP) not including 0 , and additive SI not including 1, which were calculated using the Andersson's calculation table. RERI is used to describe the magnitude of the risk attributed to the interaction, which is the absolute value of the difference between the combined effect of two factors and the sum of its individual effects. RERI $=0$ means there is no additive interaction; the larger the absolute value of RERI, the stronger interaction between factors. AP means the proportion of the total risk of the disease attributable to its interaction. When $\mathrm{SI}=1$ means there is no interaction and two factors are independent of each other; SI $>1$ means there is a positive interaction; $\mathrm{SI}<1$ means there is a negative interaction [16].

\section{Results}

\section{Baseline characteristics of the study participants}

In this study, 7282 people completed the follow-up and the average follow-up time was $6.501 \pm 2.834$ years (the follow-up time range was $1.003-8.708$ years). We identified 304 patients $(63.48 \%$ for female, average age $55.23 \pm$ 12.02 years old) having their first CHD event during the follow-up period, including three patients were under 30 years old. The incidence density of CHD was 6.42/ 1000 person-years (304/47349.16 person-years). The prevalence of metabolic syndrome was $26.96 \%$ (1963/ 7282 ) in the baseline population. Table 1 shows that in addition to family history of CHD, the other characteristics showed significant differences between the two groups $(p<0.05)$.

\section{Association between the metabolic syndrome components and CHD}

Table 2 shows that the risk of CHD increased significantly and was associated with metabolic syndrome (adjusted HR 1.81; 95\% CI 1.44-2.28), elevated blood pressure (adjusted HR 1.81; 95\% CI 1.35-2.44), and high FBG (adjusted HR 1.82; 95\% CI 1.38-2.38), however, there were no significant differences were found for high TG and low HDL-C $(p<0.05)$.

\section{Interactions among components of metabolic syndrome on the risk of $\mathrm{CHD}$}

The multiplicative interactions of elevated FBG and elevated blood pressure, and the effects of their coexistence effects with other components on the risk of CHD are shown in Table 3. The cumulative effect of elevated FBG and elevated blood pressure increased the risk of $\mathrm{CHD}$ (adjusted HR 3.51; 95\%CI 2.37-5.19). The cumulative effects between other components and elevated FBG increased the risk of CHD (adjusted HR 3.97; 95\%CI 2.426.51). The cumulative effects between other components and elevated blood pressure increased the risk of CHD (adjusted HR 3.58; 95\%CI 2.49-5.15). However, the multiplicative interaction was not significant between elevated FBG and elevated blood pressure (multiplicative SI 0.79; 95\%CI 0.39-1.58), elevated blood pressure and other components (multiplication SI 1.50; 95\% CI 0.762.77), elevated FBG and other components (multiplication SI 1.91; 95\% CI 0.67-3.43).

The following three groups of factors had positive additive interactions for CHD when they coexist, but none had statistical significance: elevated FBG and elevated blood pressure (RERI 0.25, 95\%CI -1.23-1.73; AP 0.08 , 95\%CI -0.39-0.56; additive SI 1.14, 95\%CI 0.51$2.51)$, elevated blood pressure and other components (RERI 0.344, 95\%CI -0.28-0.97; AP 0.23, 95\%CI -0.250.72; additive SI 3.54, 95\%CI 0.01-3.68), elevated FBG and other components (RERI 0.63, 95\%CI -0.34-1.60; AP 0.38 , 95\% CI -0.19-0.94; additive SI 22.94, 95\%CI 0.00117.99) (Table 4).

Table 1 Baseline Characteristics of the Study Participants

\begin{tabular}{llll}
\hline Characteristics & Without metabolic syndrome $(n=5319)$ & With metabolic syndrome $(n=1963)$ & $p$ \\
\hline Age (year) & $38.19 \pm 14.50$ & $46.32 \pm 13.44$ & $<0.001$ \\
Sex (Male), $\mathrm{n}(\%)$ & $2587(48.64)$ & $773(39.38)$ & $<0.001$ \\
Smoking status, $\mathrm{n}(\%)$ & $1228(23.09)$ & $155(7.90)$ & $<0.001$ \\
Alcohol consumption, $\mathrm{n}(\%)$ & $348(6.54)$ & $131(6.67)$ & 0.043 \\
Family history of CHD, $\mathrm{n}(\%)$ & $321(6.03)$ & $42(2.14)$ & 0.316 \\
Family history of diabetes, $\mathrm{n}(\%)$ & $75(1.41)$ & $487(24.81)$ & 0.028 \\
Family history of hypertension, $\mathrm{n}(\%)$ & $1121(21.08)$ & $148(7.54)$ & 0.001 \\
Incidence of CHD, $\mathrm{n}(\%)$ & $156(2.93)$ & & $<0.001$ \\
\hline
\end{tabular}

CHD coronary heart disease 
Table 2 The association between metabolic syndrome components and coronary heart disease

\begin{tabular}{llllll}
\hline Components & $\mathrm{N}$ & $\mathrm{CHD}, \mathrm{n}(\%)$ & $\mathrm{HR}^{\mathrm{a}}(95 \% \mathrm{Cl})$ & $\mathrm{HR}^{\mathrm{b}}(95 \% \mathrm{Cl})$ & $\mathrm{HR}{ }^{\mathrm{c}}(95 \% \mathrm{Cl})$ \\
\hline Large waistline & 3583 & $202(66.45)$ & $2.23(1.76-2.84)$ & $1.42(1.10-1.83)$ & $1.28(0.99-1.66)$ \\
High TG & 1382 & $73(24.01)$ & $1.45(1.11-1.89)$ & $1.26(0.97-1.64)$ & $1.08(0.82-1.41)$ \\
Low HDL-C & 3661 & $152(50.00)$ & $1.04(0.83-1.31)$ & $1.07(0.85-1.34)$ & $1.07(0.85-1.35)$ \\
Elevated blood pressure & 3821 & $242(79.61)$ & $3.73(2.82-4.93)$ & $1.92(1.44-2.58)$ & $1.81(1.35-2.44)$ \\
Elevated FBG & 850 & $72(23.68)$ & $2.78(2.14-3.63)$ & $1.94(1.49-2.54)$ & $1.82(1.38-2.38)$ \\
Metabolic syndrome & 1963 & $148(48.68)$ & $2.99(2.39-3.75)$ & $1.81(1.44-2.28)$ & - \\
\hline
\end{tabular}

FBG fasting blood glucose, $H D L-C$ high-density lipoprotein cholesterol, $T G$ triglycerides, $C H D$ coronary heart disease, $H R$ hazard ratios, $C l$ confidence interval. Large waistline $\geq 90 / 80 \mathrm{~cm}$; high TG $\geq 1.7 \mathrm{mmol} / \mathrm{L}$; low $\mathrm{HDL}-\mathrm{C}<1.04 / 1.30 \mathrm{mmol} / \mathrm{L}$; elevated blood pressure $\geq 130 / 85 \mathrm{mmHg}$; elevated $\mathrm{FBG} \geq 5.6 \mathrm{mmol} / \mathrm{L}$.

a Without adjustment

${ }^{b}$ Adjustment for alcohol consumption, smoking status, age, sex and family history of hypertension, family history of diabetes and family history of coronary heart disease

c Adjustment for alcohol consumption, smoking status, age, sex and family history of hypertension, family history of diabetes and family history of coronary heart disease, and the other risk factors (i.e., large waistline, high TG, low HDL-C, elevated blood pressure and elevated FBG)

\section{Association between metabolic syndrome component number and CHD}

Table 5 shows that set one component as the reference group, in participants with 3 to 5 components, the HRs of CHD gradually increased, the adjusted HR is 1.94 $(1.38-2.74)$ to $4.28(2.42-7.56)$.

\section{The association between different combinations of} metabolic syndrome components and CHD

The components of metabolic syndrome in diagnosed patients could be amalgamated into 15 different combinations. When the number of components was 3 , high TG+ low HDL-C + elevated blood pressure was taken as the reference group. We found large waistline + elevated FBG+ high TG (adjusted HR 2.37; 95\% CI 0.43-12.99), large waistline + elevated FBG+ low HDL-C (adjusted
HR 2.39; 95\% CI 0.43-13.12), large waistline + elevated blood pressure + low HDL-C (adjusted HR 1.62; 95\% CI 0.58-4.49), large waistline + elevated blood pressure + elevated FBG (adjusted HR 1.57; 95\% CI 0.50-4.94), large waistline + elevated blood pressure + high TG (adjusted HR 1.88; 95\% CI 0.60-5.84), elevated blood pressure + elevated FBG+ low HDL-C (adjusted HR 2.30; 95\% CI 0.62-8.58) had higher risk of CHD, however, there were no significant difference.

When the number of components was 4 and set high TG+ low HDL-C+ elevated blood pressure + large waistline as the reference group. We found high TG+ low HDL-C+ elevated FBG+ large waistline (adjusted HR 4.26; 95\% CI 1.43-12.73), and elevated blood pressure + elevated FBG+ low HDL-C+ large waistline (adjusted HR 2.23; 95\% CI 1.08-4.59) can significantly increase risk of CHD (Table 6).

Table 3 Multiplicative interactions among components of metabolic syndrome on the risk of coronary heart disease

\begin{tabular}{|c|c|c|c|c|}
\hline Interaction items & $\mathrm{N}$ & CHD, n (\%) & $\mathrm{HR}^{\mathrm{b}}(95 \% \mathrm{Cl})$ & $\begin{array}{l}\text { Multiplicative } \\
\mathrm{SI}^{\mathrm{b}}(95 \% \mathrm{Cl})\end{array}$ \\
\hline Elevated FBG ${ }^{-}$/ Elevated blood pressure ${ }^{-}$ & 3168 & $50(1.58)$ & 1 (ref) & $0.79(0.39-1.58)$ \\
\hline Elevated FBG ${ }^{+}$/ Elevated blood pressure ${ }^{-}$ & 3264 & $182(5.58)$ & $1.95(1.41-2.70)$ & \\
\hline Elevated FBG ${ }^{-}$/ Elevated blood pressure ${ }^{+}$ & 293 & $12(4.1)$ & $2.29(1.22-4.30)$ & \\
\hline Elevated FBG ${ }^{+} /$Elevated blood pressure ${ }^{+}$ & 557 & $60(10.77)$ & $3.51(2.37-5.19)$ & \\
\hline Elevated blood pressure ${ }^{-} /$Other components ${ }^{-}$ & 3100 & $49(1.58)$ & 1 (ref) & $1.50(0.76-2.77)$ \\
\hline Elevated blood pressure ${ }^{+}$/ Other components ${ }^{-}$ & 2464 & $159(6.45)$ & $2.65(1.51-4.63)$ & \\
\hline Elevated blood pressure ${ }^{-} /$Other components ${ }^{+}$ & 299 & $13(4.35)$ & $1.00(0.57-1.75)$ & \\
\hline Elevated blood pressure ${ }^{+} /$Other components ${ }^{+}$ & 1115 & $83(7.44)$ & $3.97(2.42-6.51)$ & \\
\hline Elevated $\mathrm{FBG}^{-}$/ Other components ${ }^{-}$ & 4896 & $144(2.94)$ & 1 (ref) & $1.91(0.67-3.43)$ \\
\hline Elevated $\mathrm{FBG}^{+} /$Other components ${ }^{-}$ & 668 & $64(9.58)$ & $1.55(0.74-3.25)$ & \\
\hline Elevated FBG ${ }^{-} /$Other components ${ }^{+}$ & 1304 & $88(6.75)$ & $1.21(0.90-1.65)$ & \\
\hline Elevated $\mathrm{FBG}^{+} /$Other components ${ }^{+}$ & 110 & $8(7.27)$ & $3.58(2.49-5.15)$ & \\
\hline
\end{tabular}

FBG fasting blood glucose, $C H D$ coronary heart disease, $H R$ hazard ratio, $\mathrm{Cl}$ confidence interval. Other components, one or more components are abnormal among the three components except blood sugar and blood pressure (large waistline, high TG, low HDL-C)

$\mathrm{N}$ is the number of participants in the interaction items. ${ }^{\mathrm{b}}$ Adjustment for alcohol consumption, smoking status, age, sex and family history of hypertension, family history of diabetes and family history of coronary heart disease 
Table 4 Additive interactions among components of metabolic syndrome on the risk of coronary heart disease

\begin{tabular}{|c|c|c|c|}
\hline \multirow[t]{2}{*}{ Interactive items } & \multicolumn{3}{|l|}{ Additive interaction } \\
\hline & $\mathrm{RERI}^{\mathrm{b}}(95 \% \mathrm{Cl})$ & $\mathrm{AP}^{\mathrm{b}}(95 \% \mathrm{Cl})$ & $\mathrm{SI}^{\mathrm{b}}(95 \% \mathrm{Cl})$ \\
\hline Elevated FBG \& Elevated blood pressure & $0.25(-1.23-1.73)$ & $0.08(-0.39-0.56)$ & $1.14(0.51-2.51)$ \\
\hline Elevated blood pressure \& Other components & $0.34(-0.28-0.97)$ & $0.23(-0.25-0.72)$ & $3.54(0.01-3.68)$ \\
\hline Elevated FBG \& Other components & $0.63(-0.34-1.60)$ & $0.38(-0.19-0.94)$ & $22.94(0.01-17.99$ \\
\hline
\end{tabular}

FBG fasting blood glucose, $C H D$ coronary heart disease, $H R$ hazard ratios, $C l$ confidence interval, $R E R I$ relative excess risk due to interaction, $A P$ attributable proportion of interaction, $S /$ synergy index

${ }^{\mathrm{b}}$ Adjustment for alcohol consumption, smoking status, age, sex and family history of hypertension, family history of diabetes and family history of coronary heart disease

\section{Discussion}

The underlying pathology of CHD is progressive stenosis of the coronary arteries due to arteriosclerosis (AS), which is promoted by inflammation, lipid metabolism disorders, and oxidative stress. A Japanese cohort study found that patients with metabolic syndrome had a great risk of arteriosclerosis, with an odds ratio of 2.07 (95\% CI 1.62-2.27) [17]. We found that patients who had metabolic syndrome were 1.81 times more likely to have CHD risk compared to individuals without metabolic syndrome after adjusting for alcohol consumption, smoking status, age, sex, and family history of hypertension, diabetes and CHD. Due to differences in study populations and varying definitions of metabolic syndrome, although the degree of effect of metabolic syndrome in various studies were different, they were all concordant with the present study regard to the finding that metabolic syndrome is a risk factor for CHD. A study comprised of 12,403 patients showed that mandatory diagnostic requirements for $(\geq 3)$ risk factors for metabolic syndrome, which can cause the predictive value of these factors to be lost completely or partly [18]. The present study solidifies the view that metabolic syndrome has a weaker impact on CHD than elevated blood pressure and elevated FBG after adjusting the components using multivariate analysis. It has been pointed out that the presence of metabolic syndrome per se has no better predictive value than some of its components, and this might be attributable to the action of these components as independent risk factors [19].

Table 5 Association between metabolic syndrome component number and coronary heart disease

\begin{tabular}{llll}
\hline Number of components & $\mathrm{CHD}, \mathrm{n}(\%)$ & $P$ & $\mathrm{HR}^{\mathrm{b}}(95 \% \mathrm{Cl})$ \\
\hline 1 component & $53(17.43)$ & $1(\mathrm{ref})$ \\
2 components & $86(28.29)$ & $1.28(0.90-1.80)$ \\
3 components & $92(30.26)$ & & $1.94(1.38-2.74)$ \\
4 components & $40(13.16)$ & & $2.14(1.41-3.25)$ \\
5 components & $16(5.26)$ & $<0.001$ & $4.28(2.42-7.56)$ \\
\hline
\end{tabular}

$P$ for trend test of the 1-5 components. ${ }^{\mathrm{b}}$ Adjustment for alcohol consumption, smoking status, age, sex and family history of hypertension, family history of diabetes and family history of CHD
Metabolic syndrome, as a representative disease, is defined by a group of factors that share common underlying pathological mechanisms. Insulin resistance has an indisputable role in the basis of metabolic syndromerelated pathophysiology; the mechanisms of this adverse effect is acceleration of the production of circulating malondialdehyde-modified low density lipoprotein and impairment of endothelial function [20]. We found that elevated FBG (adjusted HR 1.82; 95\% CI 1.38-2.38) increased the risk of CHD, studies have reported that FBG is a better marker of insulin resistance, which might be because inflammation and impaired endothelial function worsen the risk of CHD [18, 21]. Previous research on $\mathrm{CHD}$ and the metabolic syndrome components reported different conclusions, mostly in relation to about whether blood pressure plays a pivotal role in the progression of CHD $[22,23]$. The present study demonstrated that blood pressure is a sensitive independent predictor of CHD in this population.

One research study on 1548 patients who received elective coronary artery bypass grafting showed that higher HDL-C did not show protective effects in secondary prevention of coronary heart disease [24]. Therefore, there is still some controversy about the mechanism by which a high HDL-C level helps prevent CHD. We did not observe any association between hyper-triglyceridemia and CHD, although epidemiological evidence of the association between elevation of TG and the development of CHD had been confirmed [25], some previous studies were contrary to this association [26, 27]. Furthermore, central obesity is a core component of the diagnostic criteria of metabolic syndrome and a risk factor for chronic diseases. However, there was disagreement on any link between a large waistline, as an indicator of central obesity, and the development of CHD [28, 29]. Despite the present study not found that the above components are related to development of CHD, their effect on CHD cannot be ignored, and observed effect might be related to the optimal cutoffs in this population. Our previous research proved that there was an ideal cut-off point of waistline girth for Uighurs [30]. Further research is required to determine whether components defined by different cut-off points have different effects on the risk of CHD in order to 
Table 6 The association between different combinations of metabolic syndrome components and CHD

\begin{tabular}{|c|c|c|c|c|c|}
\hline 3 & Combinations of metabolic syndrome components & $\mathrm{N}$ & $\mathrm{CHD}, \mathrm{n}(\%)$ & $P$ & $\mathrm{HR}^{\mathrm{b}}(95 \% \mathrm{Cl})$ \\
\hline & High TG+ low HDL-C+ elevated FBG & 17 & $0(0)$ & - & - \\
\hline & High TG+ low HDL-C + elevated blood pressure & 105 & $4(3.81)$ & 0.851 & $1(r e f)$ \\
\hline & Large waistline + elevated blood pressure + low HDL-C & 663 & $12(1.81)$ & 0.002 & $1.62(0.58-4.49)$ \\
\hline & Large waistline + elevated blood pressure + elevated FBG & 130 & $50(38.46)$ & $<0.001$ & $1.57(0.50-4.94)$ \\
\hline & Large waistline + elevated blood pressure + high TG & 124 & $11(8.87)$ & 0.014 & $1.88(0.60-5.84)$ \\
\hline & Large waistline + elevated FBG+ high TG & 19 & $2(10.53)$ & 0.166 & $2.37(0.43-12.99)$ \\
\hline & Large waistline + elevated FBG+ low HDL-C & 48 & $2(4.17)$ & 0.998 & $2.39(0.43-13.12)$ \\
\hline & Elevated blood pressure + elevated FBG+ high TG & 24 & $1(4.17)$ & 0.998 & $0.83(0.09-7.47)$ \\
\hline & Elevated blood pressure + elevated FBG+ low HDL-C & 53 & $5(9.43)$ & 0.055 & $2.30(0.62-8.58)$ \\
\hline & High TG+ low HDL-C+ large waistline & 194 & $5(2.58)$ & 0.260 & $0.94(0.25-3.52)$ \\
\hline \multirow[t]{5}{*}{4} & Elevated blood pressure + elevated FBG+ Low HDL-C+ high TG & 17 & $0(0)$ & - & - \\
\hline & High TG+ low HDL-C+ elevated blood pressure + large waistline & 306 & $17(5.56)$ & 0.217 & 1 (ref) \\
\hline & High TG+ low HDL-C+ elevated FBG+ large waistline & 34 & $4(11.76)$ & 0.027 & $4.26(1.43-12.73)$ \\
\hline & Elevated blood pressure + elevated FBG+ low HDL-C+ large waistline & 97 & $13(13.83)$ & $<0.001$ & $2.23(1.08-4.59)$ \\
\hline & Elevated blood pressure + elevated FBG+ high TG+ large waistline & 41 & $6(14.63)$ & 0.001 & $2.20(0.87-5.59)$ \\
\hline
\end{tabular}

FBG fasting blood glucose, $H D L-C$ high-density lipoprotein cholesterol, $T G$ triglycerides, $C H D$ coronary heart disease, $H R$ hazard ratios, $C l$ confidence interval. $\mathrm{N}$ is the number of participants in the combination of components. $P$ is the result of Chi-square test of different combinations of components and coronary heart disease

${ }^{b}$ Adjustment for alcohol consumption, smoking status, age, sex and family history of hypertension, family history of diabetes and family history of coronary heart disease

obtain more appropriate diagnostic criteria for this population, to better screen high-risk groups, and to promote the prevention of chronic diseases in Xinjiang.

A prospective study on the general Asian population in general confirmed that the presence of coexistent impaired fasting glucose and prehypertension leads to an increase in the incidence of cardiovascular diseases [31]; a German (DIG) study also found this phenomenon for the combination of diabetes and hypertension [32]. On investigating interaction of elevated FBG and elevated blood pressure on $\mathrm{CHD}$, we found a negative multiplicative interaction (multiplicative SI 0.79; 95\%CI 0.39-1.58) and a positive additive interaction (additive SI 1.14, 95\%CI 0.51-2.51), none of these interactions have significant differences. Studies showed that when biological interactions were discussed, the additive interactions were more credible if multiplicative interactions and additive interactions conflicted [33]. Although there was no significant biological interaction between elevated FBG and blood pressure, there was a positive effect for CHD. That suggested that elevated FBG and elevated blood pressure have independent effects on the development of CHD in this population of Xinjiang.

Current research found that the aggregation of metabolic syndrome components can heighten the risk of $\mathrm{CHD}$. As the number of components increased, there were corresponding increases of adjusted HR of CHD. A prospective cohort of CHD in Iran also obtained this result [7], and a cohort in China reached the same conclusion for cardiovascular disease [22]. When the number of components was the same, this study found that there are different correlations of component combinations with the risk of CHD. Further observed indicate that each combination which increase the risk of CHD involves large waistline. Prior studies suggested that participants with abnormal waistline girth $(\geq 90 \mathrm{~cm}$ in males/ $\geq 85 \mathrm{~cm}$ in females) are at higher risk for 10year-CHD (odds ratio $=3.168$ ) in Tibet and Xinjiang [34]. Furthermore, the prevalence of hypertension and obesity in Xinjiang was significantly higher than the national average level $[14,35]$, and there was a high number of patients with CHD in this study (hypertension 242/304 and central obesity 202/304). Therefore, for primary prevention of $\mathrm{CHD}$ in this population, comprehensive prevention measures should be implemented for the management and treatment of elevated blood pressure, elevated FBG and obesity (especially central obesity).

\section{Limitations}

This study has some limitations. First, the cumulative incidence of CHD may have been underestimated because the study did not include patients with CHD events who did not attend local hospitals for various reasons. Second, although we attempted to use impartial questionnaires, bias from self-reporting is inevitable. Third, the measurement of metabolic syndrome did not include all the possible components, such as inflammation, impaired glucose metabolism, insulin resistance, to name a few. This study was a long-term cohort study on CHD conducted in Xinjiang rural populations, and the data, 
which was obtained from national medical examination records as well as from hospital and social security sources, was reliable and accurate; this fact partly mitigates the above limitations.

\section{Conclusion}

This study showed that the elevated blood pressure and elevated FBG are independent risk factors that increase the risk of $\mathrm{CHD}$. Although our findings suggested that interactions between the metabolic syndrome components do not affect the risk of CHD, their effects on CHD cannot be ignored. The lack of significant biological interaction might be caused by the optimal cutoff points selected, or it might due to insufficient sample size. The hazard ratios of CHD increased with the number of metabolic syndrome components. Further observed combinations pointed out that large waistline already involves each combination. Therefore, it is important to instigate measures to control blood pressure, blood glucose, and obesity for the prevention of CHD in this population.

\section{Abbreviations}

CHD: Coronary heart disease; HR: Hazard ratio; Cl: Confidence interval; SI: Synergy index; FBG: Fasting blood glucose; TG: Triglyceride; HDL -C: Highdensity lipoprotein cholesterol; RERI: Relative excess risk due to interaction; AP: Attributable proportion of interaction

\section{Acknowledgements}

We would like to express our sincere gratitude to all those who accepted to be involved in this study.

\section{Authors' contributions}

We thank all the individuals who participated in the present study. Concept and design: SG CL and JH; acquisition of data: $W B, X Z, X W, J Z, K W, Y H, L M$, YY, JM, YS, HG and RM; drafted the manuscript: $C L$ and $J H$; statistical analysis: $\mathrm{CL}$ and $\mathrm{JH}$; editing paper: SG and RM. All authors revised the manuscript and read and approved the final version.

\section{Funding}

This study was funded by the National Natural Science Foundation of China (No.81560551). The funder had no role in the design of the study, in the collection, analysis, and interpretation of the data, or in the writing or approval of the manuscript.

\section{Availability of data and materials}

The datasets are available from the corresponding author on reasonable request. The Chinese questionnaire copy may be requested from the authors.

\section{Ethics approval and consent to participate}

This study was approved by the Ethical Review Board of the First Affiliated Hospital of Shihezi University School of Medicine (IERB No. SHZ2010LL01). Participants gave their written informed consent to confirm their involvement prior to data collection.

\section{Consent for publication}

Not Applicable.

\section{Competing interests}

The authors declare that they have no competing interests.
Received: 2 September 2019 Accepted: 29 March 2020

Published online: 25 April 2020

\section{References}

1. Zeng $X$, Jinlei $Q$, Peng $Y$, Lijun W, Yuning $L$, Jiangmei $L$, Youg Z, Xiaofeng $L$. Report on disease burden of Chinese and provincial administrative regions from 1990 to 2016. Chin Circ J. 2018;33(12):1147-58.

2. Grundy SM, Cleeman JI, Daniels SR, Donato KA, Eckel RH, Franklin BA, Gordon DJ, Krauss RM, Savage PJ, Smith SC Jr, et al. Diagnosis and management of the metabolic syndrome. An American Heart Association/ National Heart, Lung, and Blood Institute scientific statement. Executive summary. Cardiol Rev. 2005;13(6):322-7.

3. Alberti KG, Eckel RH, Grundy SM, Zimmet PZ, Cleeman II, Donato KA, Fruchart JC, James WP, Loria CM, Smith SC Jr. Harmonizing the metabolic syndrome: a joint interim statement of the international diabetes federation task force on epidemiology and prevention; National Heart, Lung, and Blood Institute; American Heart Association; world heart federation; international atherosclerosis society; and International Association for the Study of obesity. Circulation. 2009;120(16):1640-5.

4. Chien KL, Hsu HC, Sung FC, Su TC, Chen MF, Lee YT. Metabolic syndrome as a risk factor for coronary heart disease and stroke: an 11-year prospective cohort in Taiwan community. Atherosclerosis. 2007:194(1):214-21.

5. Laclaustra M, Ordonez B, Leon M, Andres EM, Cordero A, Pascual-Calleja I, Grima A, Luengo E, Alegria E, Pocovi M, et al. Metabolic syndrome and coronary heart disease among Spanish male workers: a case-control study of MESYAS. Nutr Metab Cardiovasc Dis. 2012;22(6):510-6.

6. Gami AS, Witt BJ, Howard DE, Erwin PJ, Gami LA, Somers VK, Montori VM. Metabolic syndrome and risk of incident cardiovascular events and death: a systematic review and meta-analysis of longitudinal studies. J Am Coll Cardiol. 2007:49(4):403-14

7. Esteghamati A, Hafezi-Nejad N, Sheikhbahaei S, Heidari B, Zandieh A, Ebadi M, Nakhjavani M. Risk of coronary heart disease associated with metabolic syndrome and its individual components in Iranian subjects: a matched cohort study. J Clin Lipidol. 2014;8(3):279-86

8. Suzuki T, Zeng Z, Zhao B, Wei Z, Tanabe M, Shimbo T, Kajio H, Kato N, Naruse M. Comparison of coronary heart disease risk among four diagnostic definitions of metabolic syndrome. J Endocrinol Investig. 2016:39(11):1337-46.

9. Zhang Y, Hong J, Gu W, Gui M, Chen Y, Zhang Y, Chi Z, Wang W, Li X, Ning $\mathrm{G}$. Impact of the metabolic syndrome and its individual components on risk and severity of coronary heart disease. Endocrine. 2009;36(2):233-8.

10. Guo J, Zhou T, Tao L, Huo D, Li L, Luo Y. Correlation between components and different combinations of metabolic syndrome and coronary heart disease. Chin J Public Health. 2016;32(5):632-6.

11. Weihong G, Lei Y. In: Bureau XS, editor. Xinjiang Statistical Yearbook: China Statistics Publishing house; 2018.

12. Shuxia $G, N a$ L, Jiang $C$, Jingyu $Z$, Shangzhi $X$, Heng $G$, Qiang $N$, Yihua $Z$, Feng S, Yulei D. study on relation of hypertension, high blood glucose and high blood lipid with different BMI among. Chin J Public Health. 2008;03: 279-81.

13. Guo H, Ru-Lin MA, Zhang JY, Rui DS, Shang-Zhi XU, Sun F. Comparative analysis of epidemic characteristic of metabolic syndrome of Kazakh and Hans in Xinjiang Chinese. J Hypertens. 2011:538-43.

14. He J, Guo S, Liu J, Zhang M, Ding Y, Zhang J, Li S, Xu S, Niu Q, Guo H, et al. Ethnic differences in prevalence of general obesity and abdominal obesity among low-income rural Kazakh and Uyghur adults in far western China and implications in preventive public health. PLoS One. 2014;9(9):e106723.

15. Wen J, Yang J, Shi Y, Liang Y, Wang F, Duan X, Lu X, Tao Q, Lu X, Tian Y, et al. Comparisons of different metabolic syndrome definitions and associations with coronary heart disease, stroke, and peripheral arterial disease in a rural Chinese population. PLoS One. 2015;10(5):e0126832.

16. Rothman KJ, Greenland S, Lash TL. Modern epidemiology. In: Lippincott Williams \& Wilkins. 3rd ed; 2008. p. 71-85.

17. Ohnuki T, Takahashi W, Ohnuki Y, Kawada S, Takizawa S. Significance of the presence of metabolic syndrome in patients with asymptomatic arteriosclerosis affecting the aorta and the cerebral, extra-cranial carotid and coronary arteries. Internal Med (Tokyo, Japan). 2013:52(5):523-7.

18. Younis A, Goldkorn R, Goldenberg I, Geva D, Tzur B, Mazu A, Younis A, Fisman Z, Tannenbaum A, Klempfner R. Impaired Fasting Glucose Is the Major Determinant of the 20-Year Mortality Risk Associated With Metabolic Syndrome in Nondiabetic Patients With Stable Coronary Artery Disease. J Am Heart Assoc. 2017;6(11). 
19. Ding EL, Smit LA, Hu FB. The metabolic syndrome as a cluster of risk factors: is the whole greater than the sum of its parts? : Comment on "the metabolic syndrome, its component risk factors, and progression of coronary atherosclerosis". Arch Intern Med. 2010;170(5):484-5.

20. Mizuno T, Matsui H, Imamura A, Numaguchi Y, Sakai K, Murohara T, Okumura K. Insulin resistance increases circulating malondialdehydemodified LDL and impairs endothelial function in healthy young men. Int J Cardiol. 2004;97(3):455-61.

21. Bhat SL, Abbasi FA, Blasey C, Reaven GM, Kim SH. Beyond fasting plasma glucose: the association between coronary heart disease risk and postprandial glucose, postprandial insulin and insulin resistance in healthy, nondiabetic adults. Metab Clin Exp. 2013;62(9):1223-6.

22. Kang G, Guo L, Guo Z, Hu X, Wu M, Zhou Z. Impact of blood pressure and other components of the metabolic syndrome on the development of cardiovascular disease. Circ J. 2010;74(3):456

23. Hadaegh F, Mohebi R, Cheraghi L, Tohidi M, Moghaddam NB, Bozorogmanesh M, Sheikholeslami F, Azizi F. Do different metabolic syndrome definitions predict cerebrovascular events and coronary heart disease independent of their components?: 9 years follow-up of the Tehran lipid and glucose study. Stroke. 2012;43(6):1669-71.

24. Angeloni E, Paneni F, Landmesser U, Benedetto U, Melina G, Luscher TF, Volpe M, Sinatra R, Cosentino F. Lack of protective role of HDL-C in patients with coronary artery disease undergoing elective coronary artery bypass grafting. Eur Heart J. 2013;34(46):3557-62.

25. Morrison A, Hokanson JE. The independent relationship between triglycerides and coronary heart disease. Vasc Health Risk Manag. 2009:5(1): 89-95.

26. Chen Q, Zhang Y, Ding D, Li D, Xia M, Li X, Yang Y, Li Q, Hu G, Ling W. Metabolic syndrome and its individual components with mortality among patients with coronary heart disease. Int J Cardiol. 2016;224:8-14.

27. Qiao Q, Laatikainen T, Zethelius B, Stegmayr B, Eliasson M, Jousilahti P. Tuomilehto J. Comparison of definitions of metabolic syndrome in relation to the risk of developing stroke and coronary heart disease in Finnish and Swedish cohorts. Stroke. 2009;40(2):337-43.

28. Rana JS, Arsenault BJ, Despres JP, Cote M, Talmud PJ, Ninio E, Wouter Jukema J, Wareham NJ, Kastelein JJ, Khaw KT, et al. Inflammatory biomarkers, physical activity, waist circumference, and risk of future coronary heart disease in healthy men and women. Eur Heart J. 2011;32(3): 336-44.

29. Flint AJ, Rexrode KM, Hu FB, Glynn RJ, Caspard H, Manson JE, Willett WC, Rimm EB. Body mass index, waist circumference, and risk of coronary heart disease: a prospective study among men and women. Obes Res Clin Pract. 2010;4(3):e163-246.

30. He J, Ma R, Liu J, Zhang M, Ding Y, Guo H, Mu L, Zhang J, Wei B, Yan Y, et al. The Optimal Ethnic-Specific Waist-Circumference Cut-Off Points of Metabolic Syndrome among Low-Income Rural Uyghur Adults in Far Western China and Implications in Preventive Public Health. Int J Environ Res Public Health. 2017:14(2)

31. Kokubo Y, Okamura T, Watanabe M, Higashiyama A, Ono Y, Miyamoto Y, Furukawa Y, Kamide K, Kawanishi K, Okayama A, et al. The combined impact of blood pressure category and glucose abnormality on the incidence of cardiovascular diseases in a Japanese urban cohort: the Suita study. Hypertens Res. 2010;33(12):1238-43.

32. Hanefeld M, Koehler C, Gallo S, Benke I, Ott P. Impact of the individual components of the metabolic syndrome and their different combinations on the prevalence of atherosclerotic vascular disease in type 2 diabetes: the diabetes in Germany (DIG) study. Cardiovasc Diabetol. 2007:6(13):1-7.

33. Clayton D, McKeigue PM. Epidemiological methods for studying genes and environmental factors in complex diseases. Lancet. 2001:358(9290):1356-60.

34. Zheng CY, Wang ZW, Chen Z, Zhang LF, Wang X, Dong Y, Nie JY, Wang JL, Shao $L$. Tian Y: [association between the types of obesity and the 10-yearcoronary heart disease risk, in Tibet autonomous region and Xinjiang Uygur autonomous region]. Zhonghua Liu Xing Bing Xue Za Zhi. 2017;38(6):721-6.

35. Wang Y, Zhang J, Ding Y, Zhang M, Liu J, Ma J, Guo H, Yan Y, He J, Wang K, et al. Prevalence of Hypertension among Adults in Remote Rural Areas of Xinjiang, China. Int J Environ Res Public Health. 2016;13(6).

\section{Publisher's Note}

Springer Nature remains neutral with regard to jurisdictional claims in published maps and institutional affiliations.

\section{Ready to submit your research? Choose BMC and benefit from:}

- fast, convenient online submission

- thorough peer review by experienced researchers in your field

- rapid publication on acceptance

- support for research data, including large and complex data types

- gold Open Access which fosters wider collaboration and increased citations

- maximum visibility for your research: over $100 \mathrm{M}$ website views per year

At $\mathrm{BMC}$, research is always in progress.

Learn more biomedcentral.com/submissions 